\title{
ENSAYOS
}




\section{UNA ÉPOCA DE POLÉMICAS: \\ Críticos y defensores de la educación católica durante la Regeneración ${ }^{*}$}

Robert V. Farrel

El presente capítulo se ocupará del estudio de los críticos y defensores del sistema educativo colombiano durante el periodo 1886-1930, así como de lo principales temas debatidos. Lo separaremos en tres partes básicas: primero se analizarán las manifestaciones más tempranas de la crítica; fue durante este período temprano, 1890, cuando empezaron a surgir los debates sobre asuntos importantes. Luego echaremos una mirada desprevenida a algunos de los principales temas y a las personalidades más directamente involucradas en ellos; $y$, por último, se considerarán los años finales de la Regeneración, los quiebres concretos en el proceso de reforma educativa, el impulso creciente de la oposición a este sistema y, finalmente, la reacción y la renuncia a actuar de parte de los católicos.

\section{El período inicial}

Se ha visto que con el surgimiento de la Regeneración hubo un cambio radical en la filosofía que regía la educación pública colombiana. La pedagogía tradicional de la Iglesia católica, con su énfasis en la religión repetitiva para las masas y un currículo tradicional para la élite, reemplazó los esfuerzos liberales previos en favor de una educación obligatoria, libre y secular. Las razones de este cambio ya se han discutido en otra parte: el oportunismo económico del gobierno conservador y la creencia de que la dominación católica del sistema escolar unificaría a un país profundamente dividido. Lo importante es que este cambio radical excluyó de la filosofía educativa a un amplio segmento de la población, aislado de los círculos del gobierno y de las aulas oficiales. Los liberales y los simpatizantes de la causa liberal se convirtieron en oponentes automáticos de las tendencias educativas de la Regeneración. A continuación se analizarán las manifestaciones abiertas de su oposición durante este período temprano, el establecimiento de escuelas de la oposición y los ataques críticos en la prensa liberal.

Sin embargo, como también se verá, los liberales no fueron la única fuente de crítica a la educación. Una oposición dc mucho mayor peso surgió en este período temprano, conformada por algunos defensores de la Constitución de 1886 y de la política de la Regeneración, pero que se habían desencantado de la evolución política, económica y educativa del nuevo régimen. Este grupo generalmente se conoce como el del conservatismo moderado. Sus ideas, así como las de su vocero más importante. Carlos Martínez Silva, se estudiarán más adelante.

La Regeneración excluyó a los liberales de los círculos oficiales y desterró su filosofía de las aulas oficiales. Con esta exclusión ocurrió un fenómeno que es extrañamente peculiar para Colombia: los liberales establecieron colegios privados para preservar su ideología política y su filosofía educativa. Por supuesto, la aparición de estos colegios fue una indicación directa de la oposición que se haría a las tendencias educativas de la Regeneración. Una discusión profunda del desarrollo e impacto de estos colegios está más allá del ámbito de este estudio. Sin embargo, más adelante se tocarán algunos

\footnotetext{
El presente ensayo constituye el capitulo VI de la disertación doctoral de Robert V. Farrel presentada a la Universidad de Columbia en 1974 con el título de The Catholic Church and Colombian Education, 18861930: in Search of a Tradition. Traducido por Enrique Hoyos Olier, profesor de la Universidad Pedagógica Nacional 
hechos sobresalientes para ilustrar los fundamentos filosóficos sobre los cuales se desarrollaron.

La mayoría de los historiadores colombianos sólo hacen breves referencias a las escuelas de oposición, pero ellas llegan a lo más significativo de la política y de la educación colombianas. El abismo entre los dos partidos principales de Colombia fue tan profundo durante el siglo XIX que la dominación política del gobierno por uno de ellos excluía totalmente el reconocimiento de la filosofía del partido adverso en el sistema escolar nacional. Por consiguiente. cuando el partido liberal estuvo en el poder, la educación fue «liberalizada». Este fenómeno ocurrió durante los años precedentes a la Regeneración cuando la norma del día era la educación obligatoria, libre y secular. Durante este período, los conservadores católicos establecieron colegios privados para preservar su ideología y sus creencias. Lo mismo ocurrió durante la Regeneración, pero esta vez fueron los liberales los que fundaron colegios privados.

Después del triunfo de Núñez. estos colegios aparecieron muy pronto en Bogotá y en otras ciudades. Establecido en 1886, El Externado había concedido cerca de mil títulos en varios campos antes de 1891. Aunque dejó dc existir durante la primera parte de 1890. pronto lo reemplazaron otras instituciones liberales, como el Liceo Mercantil y la Universidad Republicana. En muchos zonas dispersas empezaron a aparecer colegios con los nombres de «Republicano» y «Pestalozzi» incorporados ${ }^{1}$. En poco tiempo estos colegios y sus patrocinadores fueron blanco de duros ataques de la iglesia Católica en los ámbitos nacional y local, y se involucraron en el debate sobre la definición de escuelas "públicas" y "privadas".

En palabras muy sencillas, estas instituciones representaron una amenaza directa para la ortodoxia y el control de la educación por parte de la Iglesia Católica. Ellas no atacaron abiertamente a la Iglesia ni al sistema, pero la filosofía educativa que abrazaron representaba un peligro claro. La adopción liberal de la «tolerancia» y el carácter voluntario de la asistencia a las clases de religión en sus colegios entraron en conflicto con el pensamiento de la Iglesia que prescribía a todos ellos la necesidad de impartir la orientación católica ${ }^{2}$. Además, el ideal liberal de que la educación debía ser libre chocaba con la pedagogía católica. En este período temprano, escuelas como el Colegio Pestalozziano de El Socorro hicieron hincapié en que la educación debía ser «libre» de la restricción indebida y del dogmatismo ${ }^{3}$. Aquí se encuentra implícita la idea de que la verdad debe ser descubierta y no dada «automáticamente». un concepto anatematizado por la Iglesia, que se había convertido en la guardiana de la verdad basada en la revelación y el mito ${ }^{4}$.

El establecimiento de escuelas de la oposición indicaba una actitud altamente crítica de parte de los liberales hacia la ortodoxia católica en la educación pública. Los artículos y ensayos de la prensa liberal también indicaban esta postura crítica. La Regeneración había abierto un nuevo camino en la educación. Un rompimiento con el pasado liberal significaba el final de la educación laica obligatoria y un regreso a las raíces y normas

\footnotetext{
${ }^{1}$ Reglamento del Instituto Pestalozziano del Socorro (Tipografía de Ricardo Torres. 1890). 19 pp.: «Colegio Republicano de Tunja». El Autonomista, serie IV, No. 96, 29 de enero de 1899.

${ }_{2}^{2}$ Reglamento ... ibid.

3 Julio César Gómez. Reglamento del Colegio Privado Pestalozziano (Tipografía de Cancino Hermanos. 1900), p. 1.

4 «Universidad Republicana». La Crónica, año I. No. 172. 12 de noviembre de 1897, p.2 «Universidad Republicana», La Crónica, año II. No. 492, 18 de diciembre de 1898. p. 4. "Nota Editorial--La Universidad Libre». El Espectador, año XXIX. No. 1743. 12 de diciembre dc 1915. p. 3; Boletín de la Universidad Libre, serie I. No. 2. 13 de mayo de 1913. p. 3.
} 
tradicionales. Muchos aspectos de esta «nueva» educación fueron blanco de dura polémica. y gradualmente emergieron los temas principales ${ }^{5}$.

Poco a poco los liberales se desencantaron con el crecimiento cuantitativo de la educación bajo el gobierno conservador. Fueron frecuentes las comparaciones entre el "ahora» y el "entonces», entre el estatus presente de la educación colombiana bajo la política de la Regeneración y bajo la «edad de oro» del decenio de 1870. Los editoriales de los periódicos liberales revelaron algunas cifras duras. Por ejemplo, un editorial de La Crónica fechado el 27 de enero de 1899 presenta las cifras correspondientes al Departamento de Santander que indican la presencia de 22.000 estudiantes en las escuelas en 1875 en comparación con apenas un poco más de 12.000 en el presente. ¡Y esto con un crecimiento de 200.000 habitantes en el Departamento! ${ }^{6}$.

La Iglesia se defendió de estas acusaciones aduciendo que la educación en Colombia estaba en expansión a pesar de la carencia de una ley que la hacía obligatoria, y los obispos, como Manuel José Benítez de Medellín, defendieron los logros suyos desde el golpe de Núñez ${ }^{7}$. En una carta publicada a comienzos de los noventa, este prelado citaba datos estadísticos para mostrar que al menos el nivel profesional y el de la secundaria habían sido productivos en los años recientes. Se publicó una. lista en la que se mostraba que unos 400 estudiantes habían concluido sus estudios entre 1886 y 1892, y que Colombia tenía 31 escuelas de nivel secundario y profesional con una matrícula de $5.000^{8}$.

La guerra de estadísticas continuó durante los 1890 junto con un decidido interés de los liberales por la educación popular. Se organizaron grupos locales para impulsarla y en Bogotá se constituyó una Sociedad por la Educación Popular en 1899. También se dieron debates ocasionales en el Congreso sobre la educación obligatoria y la necesidad de aumentar el número de colegios disponibles para el ciudadano común ${ }^{10}$. Nada se obtuvo de estos debates; sin embargo, resulta interesante observar que los políticos conservadores católicos que se opusieron a la idea de la educación obligatoria durante los debates de los 1890 utilizaron principalmente argumentos eclesiásticos en su defensa del status quo. La Iglesia se opuso a este postulado porque veía un peligro de que ella condujera a un Estado docente y, por esa misma razón, estos políticos consideraron el concepto totalmente inaceptable ${ }^{11}$.

Durante la segunda mitad de los 1890 , la crítica liberal ganó impulso bajo el liderazgo de los periódicos de Bogotá, E/ Autonomista y La Crónica. La prensa de oposición mencionaba con frecuencia la supuesta carencia de iniciativa del gobierno en materia educativa! ${ }^{12}$. Otro aspecto fue la aparente baja calidad en el conjunto de la educación en Colombia. Se decía que la estrecha rutina y la tradición, el énfasis en la instrucción literaria y la confianza en los escritos del pasado para el descubrimiento de la verdad del presente eran la norma, no la excepción, en el campo de la educación ${ }^{13}$. Los críticos liberales se mostraron especialmente contrariados por la ausencia del «enfoque

\footnotetext{
${ }^{5}$ Véase: «Educación». Correo Nacional, serie XIII. No. 388. 13 de enero de 1892. p. 2.

${ }^{6}$ «Instrucción Regenerativa», La Crónica, año III. No. 463. 27 de enero de 1899, p. 2.

7 «Comunicados». Colombia Cristiana, año I. No. 7.23 dc noviembre de 1892. p. 66.

${ }^{8}$ Ibid.

${ }^{9}$ Reglamento de /a Sociedad de Educación Popular (Bogotá: Imprenta de la Crónica, 1899). 12 pp. Crónica, año II, No. 390, 13 de noviembre de 1898, p. 3.

${ }_{11}$ «Instrucción primaria obligatoria», E/ Autonomista, No. 45, serie II. 12 de noviembre de 1898, p. 4.

${ }^{11}$ /bid

12 «La instrucción pública». La Crónica. año II. No. 432. 22 de diciembre de 1898. p. 2.

13 «Reforma de la instrucción». El Autonomista, serie. IV. No. 85. 17 de enero de 1898. p. 2. 
científico» de los colegios y por la falta de interés generalizado por la ciencia. Estos críticos creían que la ciencia, no los clásicos, era la clave para el futuro de Colombia ${ }^{14}$.

Por último, otra área de preocupación fundamental para los liberales fue la abrumadora presencia de la Iglesia católica en la educación pública. Sin embargo, ésta era una materia extremadamente peligrosa, pues iba contra la ley el criticar públicamente la autoridad eclesiástica, y por ello muy pronto aparecieron artículos sobre este tema. Se expresó cierto resentimiento contra el nombramiento de Rafael María Carrasquilla como Ministro de Instrucción Pública en $1896^{15}$ y se hizo un esfuerzo en el Congreso para modificar el articulo constitucional que permitía tales nombramientos ${ }^{16}$. Sin embargo, habría que esperar al siglo XX para que se plasmaran los esfuerzos de secularización y nacionalización del sistema educativo público nacional.

Durante los primeros años de la Regeneración, los colegios de la oposición y la prensa liberal no fueron, de ninguna manera, la única fuente de críticas a la educación. Una muy importante, si no la más, provino de los grupos conservadores moderados. Así como los grupos de liberales moderados habían sido un centro de antagonismo y descontento durante los períodos liberales previos, los conservadores moderados se convirtieron en un núcleo similar de antagonismo y descontento durante la era conservadora. Su crítica no apareció en forma significativa sino hasta el decenio final del siglo XIX, después de la revolución de 1895 y antes de la Guerra de los Mil Días (1899-1902). El año clave para este grupo fue 1896, durante el cual la instrucción pública se convirtió en una cuestión política que los conservadores moderados incluyeron en sus criticas al gobierno de Miguel Antonio Caro.

Durante la primera parte de 1896 un grupo conservador moderado, cuyo vocero principal fue Carlos Martínez Silva, publicó un manifiesto altamente crítico del gobierno. Mejor conocido como el Manifiesto de los 21, el documento cubría un amplio rango de temas, que comprendían el sistema electoral. los impuestos, la libertad de prensa, para mencionar sólo unos pocos. Su resumen de las tendencias recientes en la educación presenta una visión altamente negativa cuando se toma en consideración que esas mismas personas alguna vez habían sido partidarias ardientes del cambio político de Nuñez ${ }^{17}$.

El Manifiesto tocó varias áreas de la educación primaria y secundaria. La carencia de iniciativa del gobierno fue un hecho claramente atribuible a la política de delegar más y más responsabilidades a la Iglesia. También se atacaron la calidad y la cantidad de la educación. El número de alumnos y de profesores del sistema era inadecuado; los materiales del colegio y las construcciones eran defectuosos, los métodos educativos arcaicos y los salarios bajos. Un señalamiento muy interesante se refería a la educación secundaria y parecía apuntar directamente a la creciente influencia de la Iglesia en esta área. De acuerdo con el Manifiesto, los colegios públicos y privados de secundaria, aunque auxiliados por fondos del gobierno, no habían empezado a sustituir a los colegios de secundaria que habían prosperado durante el régimen liberal anterior. Por último, la acusación de que los contratos monopolísticos convertían a «algunos en empresarios de

\footnotetext{
${ }^{14}$ Estos crítico liberales se parecían en su filosofía y en su pensamiento a los virreyes españoles del siglo 18. Ios que consideraban que la ciencia era la clave para el desarrollo: véase: «Algo sobre nuestra educación». El Autonomista, ser. IV. No. 164. 27 de abril de 1898. p. ${ }^{2}$ : " los colegios en Bogota». La Crónica año II No. 390, /3 de noviembre de 1898, p. 3.

${ }_{15}$ «Punto Constitucional». El Conservador. No. 14. ser. I. 28 de marzo de 1896. p. 58.

${ }^{16}$ Véase: «Reformas constitucionales». Repertorio Colombiano, vol. XVII, No. 5. marzo de 1898.

17 «Manifiesto de los 21 ». en El Derecho. año I ser. $1^{\text {a }}$. No. 29. pp. 114-116. 
la educación» (¿comunidades religiosas?), se repetiría frecuentemente durante los años venideros. El monopolio de las comunidades religiosas, como la de los Jesuitas, se convirtió en punto de coincidencia para los radicales y los reformadores de la educación.

Más tarde, ese mismo año, Carlos Martínez Silva reanudó su crítica al sistema educativo. Su famoso artículo "Estado actual de la instrucción pública en Colombia» apareció primero en la prensa colombiana a finales de septiembre ${ }^{18}$ El artículo parecía ser una reacción contra el sentimiento del gobierno de que las crisis fiscales $y$ gubernamentales habían impedido el progreso educativo en Colombia. Martínez Silva creía que lo esencial del problema consistía en una carencia evidente de iniciativa, unida a un pobre entusiasmo en los orígenes. Tuvo palabras duras contra la filosofia educativa inspirada por la Regeneración cuando escribió:

Con el triunfo de la Regeneración, la política educativa conservadora se consideró completa con la restauración de la religión en los colegios, el resto de las promesas se olvidaron. Es cierto que Cristo ha regresado a los colegios, pero es muy desafortunado que los estudiantes tengan muy poco más ${ }^{19}$.

Martínez Silva planteó preguntas claves; pero las respuestas no llegaron pronto. ¿Por qué estaban abandonadas las Escuelas Normales mientras persistía una necesidad desesperada de profesores? ¿Por qué había sólo once mil niños en los colegios en el departamento de Cundinamarca cuando la población escolar era aproximadamente de treinta mil ${ }^{20}$ ¿Por qué la preparación impartida en la secundaria era motivo de queja constante de los profesores de la universidad? ${ }^{21}$

El ataque del conservatismo moderado a la educación colombiana continuó durante los años restantes del decenio. Sin embargo, tal ataque fue obscurecido por las ideas extremas y por la política conservadora y liberal de la sociedad colombiana. Antes del fin del siglo los estudiantes que representaban las filosofías de tales extremos chocaron violentamente en Bogotá. La causa inmediata de este choque entre estudiantes de los Jesuitas y estudiantes liberales es de menor importancia. La confrontación violenta entre grupos de oposición el 19 de marzo de 1899 frente a San Bartolomé no fue ni la primera ni la última de una serie de tales confrontaciones en la historia de Colombia $^{22}$.

Sin embargo, lo que importa es que esta violencia, que precedió por escasos meses a la guerra interna más violenta de la historia de Colombia, sirvió para destacar las arraigadas y profundas diferencias político-religiosas en que estaba dividido el país. Tales diferencias se manifestaron en un sistema educativo que tendía a extremar las diferencias.

\footnotetext{
${ }^{18}$ Carlos Martínez Silva, «El estado actual de la instrucción pública». Los Hechos. 29 de septiembre de 1896. p. 2: continuó en el mismo el 2 de octubre. en la p. 2

${ }^{19}$ lbid.. 29 de septiembre de 1896.

${ }^{20}$ Ibid., 2 de octubre.

21 Ibid., 2 de octubre.

${ }^{22}$ La violencia entre estudiantes colombianos de diferentes tendencias políticas y religiosas no es rara en la historia del país. Los ataques contra las manifestaciones físicas de la dominación educativa católica, como los colegios, también es de ocurrencia común. Por último, miembros de las clases trabajadoras, ante el temor de la competencia de los productos elaborados en los talleres vocacionales e industriales de ciertos colegios católicos, a menudo participaron en estos hechos dc violencia. Por ejemplo. véanse: Cartas edificantes de la asistencia de España. año de 1910 (Burgos. 1911). pp. 271-274: «El ataque a los Hnos. Cristianos». La Sociedad, 1 de junio de 1911. p. 2: y José Ortega Torres, S. S. La obra salesiana en Colombia, tomo I (Bogotá: Escuelas Gráficas Salesianas. 1941). pp. 100- 101. Para el choque entre estudiantes liberales contra los de los Jesuitas en 1899. véase: «Al país». El Autonomista, ser. V. No. 137, 23 dc marzo de 1899. p. 2.
} 


\section{Temas fundamentales}

Hubo tres temas educativos que generaron la mayor controversia entre los extremos inflexibles de la sociedad colombiana. El primero es el que he llamado la «nacionalización» de la educación colombiana, el cual incluyó varios aspectos que encuentran un común denominador en los conceptos de independencia y poder. En respuesta a las presiones de la era moderna ( $\mathrm{y}$ a los resultados de la Guerra de los Mil Días), el Estado empezó a dar pasos cada vez más independientes en este campo, lo que a su vez estimuló en la Iglesia el temor al Estado docente. Los educadores de los colegios privados y aquellos de los colegios públicos oficiales empezaron a seguir líneas todavía más independientes, las que amenazaron las prerrogativas de la Iglesia. También en este intento por restaurar el poder educativo del Estado se hicieron esfuerzos en el Congreso para liberar a la educación pública de la dominación de la Iglesia católica, en especial con respecto a las comunidades religiosas extranjeras.

El segundo tema, como el primero, está íntimamente relacionado con la Iglesia. Tiene que ver con el debate sobre la calidad de la educación. Aquí se analizarán las acusaciones de lo poco práctica de ella y del predominio de la religión y de los clásicos en los programas académicos. Se considerará la defensa que hizo la Iglesia de su filosofía educativa tradicional.

Por último, el tercer tema en importancia tiene que ver con la cantidad y las estadísticas. Se llevaron a cabo muchas comparaciones entre el «entonces» y el «ahora» de la educación colombiana. Integrado a este debate sobre las estadísticas se encuentra el apoyo liberal a la educación obligatoria y la posición de la Iglesia de «libertad de educación», como una contramedida.

\section{Nacionalización}

Antes de la Guerra de los Mil Días, el Estado, interesado en la educación de una manera subsidiaria, delegó la mayor parte de sus responsabilidades educativas a la Iglesia y a los sectores privados. La educación pública estaba teóricamente centralizada en Bogotá en el Ministerio de Educación, pero no existían criterios orientadores centrales para la organización de los colegios, los currículos, las normas, los métodos o los programas. El aprovechamiento de las comunidades religiosas docentes en los colegios públicos era conocido por todos, y varios departamentos, por razones económicas evidentes, solicitaron activamente que estas comunidades enseñaran en sus colegios de primaria y de secundaria. La falta de planeamiento estatal y la poca dirección central fomentaron normas débiles en la educación secundaria, mientras que en el nivel universitario la tradición siguió produciendo exceso de abogados y médicos y escasez de los técnicos e ingenieros que demandaba un desarrollo moderno.

Este panorama cambió, empero, después de la Guerra de los Mil Días. Durante esta devastadora guerra, que cobró más de cien mil vidas, se cerró virtualmente el sistema de colegios públicos y privados ${ }^{23}$. Aun el famoso El Rosario fue convertido en cuartel durante parte de las hostilidades y sólo los colegios principales de ciertas comunidades religiosas permanecieron abiertos. Después de la guerra, resultó evidente que tenía que hacerse algo drástico para reavivar la educación colombiana.

\footnotetext{
${ }^{23}$ Véase: Jesús María Henao y Gerardo Arrubla, Historia de Colombia Digitalizado por RED ACADEMICA
} 
Después de la guerra, el Ministerio de Educación y el Gobierno nacional comenzaron a interesarse más por el desarrollo educativo. Durante el primer decenio del siglo XX, nuevos planes, programas y leyes restauraron y fomentaron la educación. José Joaquín Casas (hijo de Jesús Casas Rojas), el Ministro de Educación inmediatamente después del cese de hostilidades, convocó a una íntima cooperación Estado-Iglesia para reconstruir y universalizar el devastado sistema educativo ${ }^{24}$. Las iniciativas del Gobierno y del Estado centraron su atención en la educación técnica para satisfacer las necesidades urgentes del desarrollo del país ${ }^{25}$.

El siguiente Ministro de Educación, Antonio José Uribe, manifestó un interés creciente en materia técnica en la educación, y el Presidente Rafael Reyes, durante su período de 1904 a 1909, fue también un decidido defensor de la educación técnica y de la reforma educativa. Reyes estaba especialmente comprometido con el aprovechamiento de la educación en el desarrollo económico y físico de la nación. En este sentido, hace recordar a los virreyes españoles más progresistas del siglo XVIII. Reyes quiso romper el monopolio del currículo clásico en la educación secundaria, un deseo que lo puso en oposición directa con la más poderosa e influyente de las comunidades religiosas docentes, los Jesuitas ${ }^{26}$.

A comienzos del siglo se dieron iniciativas concretas en el campo de la educación técnica. La Ley Orgánica de 1903 se ocupó de todo el espectro de la educación colombiana. Este documento pretendía restaurar algún orden en la masa dispersa de la instrucción pública. No se pretendía que la Ley amenazara a la Iglesia y el artículo 1; de hecho, hacía eco del artículo 41 de la Constitución ${ }^{27}$. No obstante, al tratar de organizarla dando pasos para establecer currículos, criterios y guías, pareció amenazar el poder de la Iglesia. Resulta claro que la parte de la ley que se ocupa de la educación técnica presentaba un reto, al menos en el papel, al currículo clásico.

La Ley Orgánica demostró el interés renovado del gobierno por la educación técnica secundaria, la que en efecto recibió lugar preferencial en el sistema de la educación pública. El artículo 116 de la nueva ley definía la educación técnica secundaria como «las nociones generales de cultura, lenguas modernas y los temas necesarios para preparar para las escuelas profesionales ${ }^{28}$. El artículo siguiente a su vez daba a este tipo de educación secundaria, que hacía hincapié en las ciencias, las matemáticas y las lenguas modernas, preferencia en todos los colegios de secundaria financiados con recursos del gobierno nacional $^{29}$.

Sin embargo, a pesar del interés evidente del gobierno por la educación técnica, pasarían muchos años antes que el currículo técnico fuese competitivo con el clásico. Las presiones ejercidas por el gobierno nacional y por comunidades innovadoras, como la de

\footnotetext{
${ }^{24}$ Véase: «Resolución No. 110», Revista de instrucción Pública de Colombia, tomo XII. No. 68. agosto de 1902, pp. 11-17.

25 Héctor G. Valencia Vásquez, theories and Practices of Secondary School Organization and Administration in the Republic of Colombia (disertación doctoral; Ohio State University. 1953). p. 131.

${ }^{26}$ Véase: Sanín Cano. Administración Reyes, 1904-1909 (Lausana: Imprenta de Bridel \& Co. 1909). 404 pp: Rafael Reyes, Escritos varios (Bogotá: Tipografía Aroonvar. 1920), 544 pp.: y Eduardo Lemaitre Román, Rafael Reyes. Biografía de un gran colombiano (Bogotá: Espinel. 1967). 304 pp.

${ }^{27}$ Véase: «Ley 39 de 1903». en Código de instrucción Pública de Colombia (Bogotá: Imprenta Nacional. 1911). p. 3.

28 Ministerio de Educación Nacional. Educación Colombiana. tomo I, Disposiciones Orgánicas y Reglamentarias de la Educación Nacional en las Ramas de Primaria, Normalista Superior y Bachillerato y Otros Aspectos de Interés General, /903-1958 (Bogotá: Imprenta Nacional. 1959). p. 39.

${ }^{29} \mathrm{lbid}$. 
los Hermanos Cristianos, obligaron a introducir algunas modificaciones en el currículo clásico dominante. Pero el diploma de Bachiller en Filosofía y Letras seguiría siendo el más importante de todos hasta el final de la Regeneración; era la credencial única requerida para el ingreso a las facultades universitarias, incluidas las de ingeniería.

Las iniciativas del Estado sobre la educación continuaron durante el siglo XX. En cuanto a la reacción de la Iglesia ante este renovado interés del Estado, ella fue esporádica pero se hizo definitivamente evidente durante los primeros treinta años de este siglo. La posición católica fue clara. Con el poder y la influencia crecientes del Estado, la Iglesia temió la pérdida de su posición como la principal educadora y expresó sus temores en numerosos artículos, editoriales y pastorales. Los defensores de la Iglesia sintieron que los derechos superiores para educar, que de hecho se originaron en la prédica «ld y enseñad a todas las naciones», debían ser protegidos a toda costa contra la amenaza creciente del Estado docente. En 1928, ya próximo el final de la Regeneración, el Arzobispo Ismael Perdomo volvió a resumir y subrayar la posición tradicional de la Iglesia y sus derechos en la educación. Sin embargo, las modificaciones respondieron a una creciente presión en favor de las reformas.

Un elemento vital en la reacción defensiva católica fue el sentimiento de que la presencia dominante del Estado limitaría el poder y la independencia de los educadores privados, comprendida la Iglesia. Los Círculos católicos no estuvieron solos en esta creencia. En 1903 un periódico moderado de Bogotá indicó que, a pesar de la necesidad de la reforma, existía la voluntad de sacrificar la independencia educativa a una presencia excesiva del Estado. Este artículo se oponía a los esfuerzos estatales en favor de la estandarización de los currículos en los colegios privados ${ }^{30}$. El argumento de la preservación de la libertad e independencia de los educadores frente a las demandas en aumento del Estado en favor de la unificación de los estándares y los currículos estuvo íntimamente ligado con la posición de la Iglesia en contra del monopolio educativo del Estado. Ambos argumentos aparecieron con frecuencia en los años subsiguientes.

Mientras el Estado mostraba una tendencia creciente a la independencia educativa, muchos colombianos, tanto educadores privados como funcionarios del gobierno, mostraron también una tendencia marcada a seguir una línea independiente frente a la de la Iglesia. Los educadores liberales, por supuesto, continuaron el apoyo a su filosofía desde el comienzo de la Regeneración. No cabe duda respecto de las ideas de individuos como Iregui y Araújo en términos de su liberalismo y su anticlericalismo ${ }^{31}$. Sin embargo, con el advenimiento del siglo XX surgió un tipo más moderno de educadores que trataron de seguir una línea intermedia entre el clericalismo y el anticlericalismo. Se interesaron por mejorar la calidad general de la educación, y recibieron fuertes influencias de los Estados Unidos y de Europa. John Dewey y su «escuela activa» aparecían con fuerza en su pensamiento. Aunque no eran anticatólicos per se, dos presupuestos de este grupo llevaron al conflicto directo con la Iglesia: el elogio de la pedagogía moderna y su apoyo a la tolerancia religiosa.

Con sus raíces educativas profundamente hundidas en la tradición, los clásicos y el dogma, no podía esperarse que la Iglesia se inclinase a apoyar abiertamente la naturaleza, la observación y los sentidos como las claves de la enseñanza y el aprendizaje. Igualmente, sería esperar demasiado que en un país en el que las clases de

\footnotetext{
${ }^{30}$ Véase: «El proyecto de Ley sobre Instrucción Pública». El Nuevo Tiempo. año II. No. 390, 29 de agosto de 1903. p. 2.

${ }^{31}$ Véase: Simón Araújo. «Educación Pública». La Crónica. 19e enero de 1899. p.2 y Antonio José Iregui, et al., «Universidad Republicana», La Crónica. 18 de diciembre de 1899. 
religión eran obligatorias en los colegios públicos y eran requisito para admisión a la universidad, la Iglesia accediera a que judíos y protestantes quedaran exentos de tales clases cuando se hicieron esfuerzos para hacerlo. A medida que tomaba forma el sistema educativo colombiano para el siglo $\mathrm{XX}$, la Iglesia continuó sus protestas y advertencias contra los embates del «modernismo pedagógico» y de la tolerancia desenfrenada.

Dentro del movimiento por la reforma educativa del siglo $\mathrm{XX}$. se destacan muchos colombianos, tanto por sus ideas como por los problemas que ellas les causaron con la Iglesia. Ya hemos mencionado el interés de Antonio José Uribe y del Presidente Rafael Reyes por la educación técnica. Don Agustín Nieto Caballero, otro educador moderno que, favoreció una educación más técnica, se preocupó por la renovación de la filosofía general que había dominado la educación colombiana. Se le ha llamado el padre de la educación moderna de Colombia.

Nieto Caballero trató de ser diplomático en sus esfuerzos por instituir el cambio en la educación colombiana. Sin embargo, el conflicto con la Iglesia resultó inevitable. Las teorías de John Dewey y de la facultad de Educación de la Universidad de Columbia de Nueva York, que publicó en la prensa liberal y usó como modelo en su colegio, chocaron con los conceptos de la pedagogía católica. Su rechazo abierto a la formación de profesores en Colombia también tuvo la desaprobación de la Iglesia, puesto que la preparación de profesor estaba influida considerablemente por las comunidades religiosas femeninas y por los Hermanos Cristianos. Otro tanto resultó válido por su crítica a la tradición clásica tan firmemente apoyada por una gran parte de la Iglesia. Sin embargo, el gran problema surgió en torno a su idea de tolerancia. El Arzobispo Bernardo Herrera penalizó al Gimnasio Moderno durante los primeros años de su existencia negándole un capellán porque Nieto Caballero dejó en libertad de asistir a las clases y prácticas de la religión católica a los estudiantes no católicos ${ }^{32}$.

Durante este período, otros educadores colombianos demostraron menos sutileza en sus esfuerzos por modernizar la educación y liberarla de la influencia agobiante de la Iglesia. Aun algunos ministros de educación profesaron filosofías que tendían a ser «poco ortodoxas». Viene a la mente el nombre de Emilio Isaza por el papel que desempeñó en la presentación de un proyecto de ley en el Congreso de 1908, el cual buscaba la «nacionalización» de la educación colombiana, en otras palabras, la eliminación del clero extranjero de las aulas colombianas ${ }^{33}$. Este proyecto de ley fue derrotado abrumadoramente por las fuerzas fieles a la Iglesia. Otros funcionarios del gobierno como el Director de Educación de Antioquia, Pedro Pablo Betancourt, tampoco fueron del agrado de la Iglesia durante su período. La filosofía educativa de Betancourt y su aparente preocupación por el aquí y el ahora y por el derecho de gozar la vida y sus esfuerzos por garantizar que todos los colegios financiados por el Estado cumplieran con sus normas, fueron el blanco de muchas reacciones críticas en la prensa católica ${ }^{34}$.

Por último, debe mencionarse un educador más porque es el que parece haber tenido las mayores dificultades con la jerarquía católica. Como director de educación de Bolívar y como individuo privado, Antonio José Irisarri, luchó por la modernización de la educación colombiana, y se interesó por la actualización del equipo físico en los colegios colombianos, junto con la filosofía que guiaba la educación en los salones de clase.

\footnotetext{
${ }^{32}$ Entrevistas personales con Don Agustín Nieto Caballero en el Gimnasio Moderno de Bogotá. Julio/agosto de 1970.

33 «Proyecto de Ley sobre maestros...» anales de la Asamblea Nacional. serie. VII. No. 4. 30 de julio de 1908. p. 30.

${ }^{34}$ Por ejemplo. véase: «Pedagogía Republicana». en la Sociedad. 24 de agosto de 1912 p.2. 
También creía que las funciones de la Iglesia y del Estado en la educación no podían sobreponerse y por lo tanto ejerció los poderes educativos del Estado en una forma independiente durante el tiempo que desempeñó el cargo. Irisarri dependió de las recomendaciones de los inspectores locales del Departamento de Educación en las provincias aisladas para la contratación de profesores, minando de esta manera una prerrogativa tradicional del párroco local. Ante los requerimientos de la Iglesia del inmediato reemplazo de profesores, Irisarri defendió el derecho constitucional de los profesores al debido proceso. Fue esta actitud independiente, unida a una actitud política más liberal, la que condujo a un largo período de resentimiento entre Irisarri y el Arzobispo de Cartagena Pedro Adán Brioschi. El Arzobispo acusó a Irisarri por no respetar la autoridad eclesiástica y porque sus acciones y filosofía eran anticlericales en desafió a la Constitución y al Concordato. Aunque el Vaticano anuló en 1924 el estigma de excomunión con que Brioschi había condenado a Irisarri, el resentimiento entre estos dos hombres duró hasta la muerte de este último en los 1930.

Además de las iniciativas del Estado que indirectamente amenazaron al poder educativo de la Iglesia durante los primeros años del siglo $X X$, junto con los esfuerzos de ciudadanos colombianos para modernizar la educación pública. se dieron intentos muy directos para limitar el poder católico. Se hicieron intentos formales durante este período para eliminar la influencia y la presencia del clero extranjero y reformar aquellas partes de la Constitución que se ocupaban de la educación.

Los moderados y los liberales estaban inquietos por la gran cantidad de clero extranjero en los colegios públicos y privados. Durante el periodo liberal precedente había habido fuertes protestas contra los intentos de traer a los Hermanos Cristianos a Colombia "porque ellos eran extranjeros sin patriotismo» ${ }^{35}$. Después de la aprobación de la Constitución de 1886 y del Concordato. las puertas se abrieron en ese momento para una gran afluencia de clero extranjero a los colegios colombianos. La reacción adversa era inevitable.

Muchos pensaban que los cursos de historia y de geografía colombianas (educación cívica) deberían estar bajo el control de colombianos. En 1891 se reconoció la presencia extranjera en el sistema educativo nacional, y El Correo Nacional de Martínez Silva comenzó a insistir en que para que la educación colombiana fuera "patriótica» tenía que ser dirigida por colombianos ${ }^{36}$.

Los ataques al clero extranjero se hicieron muy frecuentes con la cuestión del patriotismo siempre a la vanguardia ${ }^{37}$. y clérigos colombianos como Rafael María Carrasquilla fueron arrastrados a la controversia en defensa de los aspectos internacionales de la Iglesia ${ }^{38}$.

Mientras la controversia crecía en las páginas de la prensa liberal y conservadora, la afluencia del clero extranjero continuaba. De hecho, los religiosos Ilenaban una necesidad desesperada de más profesores a menor costo. Esta tendencia fue rechazada por quienes no veían con claridad los motivos económicos básicos que la apoyaban. Tales críticos preguntaban por qué los educadores nacionales no eran capaces de dotar de personal a los colegios ${ }^{39}$. La respuesta es que podían, pero que el prestigio relacionado

\footnotetext{
${ }^{35}$ Adolfo Dollero, Cultura Colombiana (Bogotá: Ed. Cromos, 1930). p. 430.

${ }^{36}$ "A propósito de un libro de lectura ...», El Correo Nacional. serie. IV. No. 132.19 de febrero de 1891, p. 2.

37 «La instrucción pública en el Tolima», La Crónica, año 1. No. 171, 11 de noviembre de 1897. p. 2.

38 "El Relator y el clero», El Correo Nacional, serie XXIII, No. 751, 18 de abril de 1893.

39 «Instrucción Pública». El Correo Nacional, año VII. No. 1811. 12 de febrero de 1897 p 2 
con la profesión de enseñar no era suficientemente alto, y que los salarios de los profesores, aunque bajos, eran demasiado altos para los presupuestos locales y departamentales. La opción lógica fue «dejemos que la Iglesia lo haga». A pesar de esta objeción económica, los críticos de los 1890 pronto apuntaron a «las cantidades enormes» pagadas por el gobierno a órdenes religiosas extranjeras por «una educación deficiente» ${ }^{40}$. También se dijo que los subsidios del gobierno junto con los contratos a largo plazo con órdenes como la de los Jesuitas daban a los «profesores extranjeros» una ventaja injusta sobre los profesores nacionales ${ }^{41}$.

La controversia continuó con una intensidad cada vez mayor hasta la Guerra de los Mil Días, con esfuerzos crecientes de parte de los críticos de dividir al clero entre el nacional y el extranjero. Sin embargo, este esfuerzo falló y la afluencia del clero extranjero no se detuvo. Los liberales llevaron a cabo varios esfuerzos en el Congreso para contrarrestar esta situación y algunos ministros de orientación más liberal los apoyaron. Por ejemplo, en julio de 1908 el Ministro Emilio Isaza presentó un proyecto de ley a la Asamblea Nacional en el que se proponía que todos los profesores de primaría del país fuesen colombianos, y que todos los directores de colegios oficiales estuviesen sujetos a supervisión del Estado $^{42}$. Sin embargo, no era el momento apropiado para la secularización de la educación colombiana y el Ministro retiró su apoyo al proyecto unos días después de haberlo presentado ${ }^{43}$.

La cuestión del clero extranjero fue asunto extremadamente delicado y en el mismo año del proyecto de ley de Isaza la jerarquía colombiana defendió públicamente los aspectos internacionales de la Iglesia. Un mensaje de septiembre a los fieles culpaba a la "conspiración masónica» por los ataques recientes en contra de la Iglesia y su clero extranjero, y tachó de exageradas las aseveraciones de que la educación colombiana estaba dominada por extranjeros ${ }^{44}$. Este mensaje hizo hincapié en las contribuciones del clero católico al desarrollo educativo colombiano ${ }^{45}$.

El interés por la nacionalización de la educación siguió vivo en el Congreso ${ }^{46}$ y en 1910 un ministro de educación más o menos liberal, respondiendo a la presión pública, promulgó un decreto que establecía la obligatoriedad de que los cursos de historia y de geografía colombianas en los colegios públicos fuesen enseñados por maestros colombianos $^{47}$. Evidentemente este decreto no tuvo éxito puesto que las protestas en contra de los extranjeros que enseñaban los cursos de historia y de geografía continuaron en la prensa liberal en los $1920^{48}$ y un decreto nacional parecido fue promulgado en

\footnotetext{
40 «La instrucción pública en el Tolima», op. cit.

41 Ibid.

42 Archivo del Congreso Asamblea Nacional Constituyente y Legislativa, sesiones de 1908, Acta de las sesiones del 20 de julio al 22 de agosto. «Acta de la sesión del día 27 de julio de 1908». p. 42f: «Proyecto de Ley sobre maestros de escuelas primarias oficiales». Anales de la Asamblea Nacional. ser. VII. No. 4.30 de julio de 1908, p. 30.

${ }^{43}$ Archivo del Congreso, Asamblea Nacional Constituyente y Legislativa. 1908, tomo I. Carta dc Emilio Isaza y presidente de la Asamblea, de fecha 28 de julio de 1908, p. 289.

${ }_{44}$ «A los fieles...». El mensajero del corazón de Jesús. Órgano del Apostolado de la Oración en Colombia, tomo XVIII, ser. 7. 2 de diciembre de 1908. pp. 220-224

45 Ibid.. p. 225.

${ }^{46}$ Archivo del Congreso. Senado, 1909. tomo IV. «Asuntos Varios». comunicación del Senador .Joaquín Guell a sus colegas del Senado. 27 de agosto de 1909. folio 215.

47 «Decreto No. 946». Revista de instrucción Pública, tomo XXV. No. 11, noviembre de 1910. p. 595.

48 «El espíritu nacional en la enseñanza», El Tiempo, año XIII. 29 de diciembre de 1923.
} 
$1930^{49}$. Este decreto posterior incluyó una estipulación adicional de que sólo podrían interpretarse himnos nacionales (no la Marsellesa) en los colegios públicos colombianos. ${ }^{50}$

La idea de la nacionalización de la educación colombiana durante la Regeneración adoptó diferentes significados, pero para los más radicales uno de ellos fue claro: la eliminación del modelo educativo católico tan prevaleciente en Colombia desde $1886 .{ }^{51}$ Estos radicales se atrevieron a cuestionar el fundamento mismo del poder educativo católico, el artículo 41 de la Constitución. Los intentos de reforma de este artículo comenzaron en serio en 1917 con un esfuerzo por establecer la obligatoriedad de la educación primaria en el país; empero, todo tipo de obligatoriedad de la educación fue condenado fuertemente por la Iglesia y el proyecto de reforma no fue sometido a segundo debate en el Congreso ${ }^{52}$.

Un esfuerzo de reforma del artículo 41 en las sesiones del Congreso de 1923 resultó igualmente frustrado. El proyecto. presentado por las representaciones de Bogotá y de Cartagena, proponía que:

...la República de Colombia reconoce que la educación primaria es la base del crecimiento moral y material del pueblo. Por lo anterior, la instrucción a la que se refiere el artículo 41 de la Constitución será libre y obligatoria ${ }^{53}$.

Se acercaba rápidamente la época en que el artículo 41 sería eliminado por completo de la Constitución. Este proyecto de ley, como otros, se perdió en la comisión, pero fue una indicación clara de las tendencias de cambio.

\section{Calidad de la educación}

Las características del nuevo tipo de educación, elitista, ortodoxa, clásica, estaban lejos de ser agradables para muchos educadores y pronto fueron cuestionadas. A comienzos de los 1890, la prensa liberal acusó al gobierno de descuidar deliberadamente las artes industrial y comercial en los colegios colombianos ${ }^{54}$. Se dijo que asignaturas como latín y griego, filosofía y retórica. que dominaban los currículos, estaban concebidas para un mundo ideal, no para el duro mundo de las realidades económicas. En pocas palabras, la educación colombiana antes de 1900 fue calificada por muchos críticos de poco práctica para las necesidades de la era moderna.

Los métodos educativos empleados en los colegios públicos colombianos fueron sometidos fuertemente a la crítica durante el siglo precedente. La memorización maquinal fue muy popular. Tal método no era favorable para el desarrollo de un pensamiento crítico, el razonamiento y el análisis, y los moderados, como Carlos Martínez Silva, adoptaron una posición fuerte en su contra ${ }^{55}$.

\footnotetext{
${ }^{49}$ Ministerio de Educación Nacional, Educación Nacional, tomo I. Disposiciones .... op. cit., p. 85.

${ }^{50}$ ibid.

${ }^{51}$ Véase: «La nacionalización de la enseñanza». El Nuevo Tiempo. año XX, No. 6799, 14 de diciembre de 1921 , p. 1.

${ }^{52}$ Archivo del Congreso, Cámara, 1917, tomo II, «Proyecto de Acto Legislativo Reformatorio del Artículo 41 de la Constitución Nacional». 1 de agosto de 1917, pp. 637f-638f

${ }^{53}$ Archivo del Congreso, Cámara, 1923, tomo XVI, Proyectos Pendientes de 1923. No. 173. «Proyecto de Acto Legislativo por el cual se reforma el Artículo 41 de la Constitución». pp. 330f-334f.

${ }^{54}$ « Los colegios de Bogotá». La Crónica, año II. No. 390, 13 de noviembre de 1898. P.1.

55 Ibid 
La calidad de la educación se convirtió en el blanco de ataque de muchos grupos durante la Regeneración. Sin embargo, con mucho el asunto más candente fue la preparación inadecuada de los egresados del bachillerato. Los graduados de los colegios de secundaria encontraban grandes dificultades al enfrentarse a las exigencias y rigores del estudio en la universidad. Ya desde 1893 se había hecho un esfuerzo por resolver este problema estableciendo un examen de revisión como criterio principal para recibir un diploma de bachiller en cualquier colegio colombiano, con la excepción de San Bartolomé y El Rosario ${ }^{56}$. De esta forma, el gobierno esperaba tener el control al menos parcial de la calidad de los estudiantes admitidos a la Universidad Nacional.

El decreto \#218 de 1895 muestra que existía gran interés en seleccionar los graduados de bachillerato. Definió claramente y en detalle los cursos que debían someterse a los exámenes de admisión de cada facultad de la Universidad ${ }^{57}$. No obstante, con la aprobación de la Ley Orgánica de 1903, vemos de nuevo un regreso a una actitud de laissez faire en la educación. La Ley Orgánica declaró que el diploma de Bachiller se otorgaría después de haber cumplido el requisito de tomar un número de cursos prescritos sin un examen general ${ }^{58}$.

A finales de los 1890, aun después de los esfuerzos por establecer un proceso más estricto de selección, todavía se presentaban numerosas quejas sobre la calidad de los estudiantes que buscaban admisión a la universidad.

En su artículo «Estado actual», Martínez Silva anotó las quejas de las facultades de derecho y medicina sobre la preparación de los estudiantes de primer año en las áreas básicas como ortografía, gramática y redacción ${ }^{59}$. Después de la aprobación de la Ley Orgánica de 1903, este tipo de crítica se intensificó.

A pesar de los esfuerzos del gobierno de Reyes por rectificar la situación, continuó el cuestionamiento a la pobre preparación de los estudiantes para la universidad ${ }^{60}$. En 1908 el decano de la Facultad de Derecho de la Universidad Nacional observó que el problema había empeorado notablemente. Los estudiantes de primer año, provistos de su grado de bachiller, demostraban una ignorancia sorprendente de las nociones elementales básicas del idioma español y de su literatura ${ }^{61}$. La falta de conocimientos básicos en áreas como ciencias y matemáticas forzó al establecimiento de cursos remédiales en la Universidad. Por último, el decano observó una preparación insuficiente en los idiomas extranjeros, en especial Francés, lo que causaba una gran cantidad de problemas puesto que muchos de los libros de texto usados en la facultad estaban en esa lengua ${ }^{62}$.

Estas y otras quejas impulsaron al Ministro de Educación a recomendar mayor rigor en los exámenes en idiomas, en especial en Español para ingresar a la Universidad ${ }^{63}$. Sin embargo, el problema continuó, lo que dio por resultado una acción drástica en 1902. Un decreto ejecutivo de ese año requirió una vez más los exámenes de revisión para la

\footnotetext{
56 «Decreto No. 1342». Revista de Instrucción Pública, año II. No. 15. marzo de 1894, p. 148.

${ }^{57}$ «Decreto No. 1895». Revista de instrucción Pública de Colombia. año III. No. 25. enero de 1896. pp. 8-12.

${ }^{58}$ Ministerio de Educación Nacional. Educación Colombiana, tomo I. Disposiciones ... op. cit.. p. 39.

${ }^{59}$ Carlos Martínez Silva. «Estado actual de la instrucción pública en Colombia», Repertorio Colombiano, vol. XIV, No. 4, 1 de octubre de 1896. pp. 306-307.

60 « Véase: «Decreto No. 805 de 1905». Revista de Instrucción Publica, tomo XVII. No. 1. julio de 1905. p. 20.

${ }_{61}$ «Comunicaciones», Revista de instrucción Pública, tomo XXIII, 312. diciembre de 1908. pp. 635-639.

62 Ibid.

${ }^{63}$ ibid., p. 637. 
admisión a la Universidad Nacional ${ }^{64}$. Aunque el decreto estaba apoyado por muchos educadores católicos. entre ellos Rafael María Carrasquilla, y por los directivos de la Universidad, el doctor Cuervo Márquez, Ministro de Educación, escribió en 1914 que:

Para sorpresa de muchos, uno de los principales colegios de secundaria de Bogotá demandó al Estado en un caso ante la Corte Suprema porque el Decreto de 1912 violaba ciertos derechos concedidos al colegio en su contrato con el gobierno nacional ${ }^{65}$.

Los Jesuitas lucharon contra el decreto porque éste no solamente violaba su contrato, sino porque disminuía el prestigio relacionado con el título de bachiller que ellos otorgaban. Los Jesuitas obtuvieron un fallo favorable y el gobierno se vio obligado a revocar su decreto. Cuervo Márquez escribió que «quedó entonces como hecho establecido que una comunidad religiosa ejercía más poder que el gobierno, y que un contrato privado pesaba sobre la Constitución ${ }^{66}{ }$. Los privilegios de los Jesuitas junto con su estipendio anual para San Bartolomé continuaron por muchos años más.

Las quejas sobre la calidad de los estudiantes de secundaria continuaron durante todo el decenio, a menudo con alusiones anticlericales. Este ataque se hizo especialmente acalorado durante los debates educativos de 1916, cuando se reimprimieron en la prensa colombiana las quejas de los miembros del profesorado de la universidad ${ }^{67}$. Una vez más, las deficiencias se manifestaron en la gramática española, el latín y la filosofía, y en los métodos de investigación científica y la comprensión. No se establecieron diferencias entre colegios privados y oficiales. Ambos eran deficientes y el título de Bachiller, corno indicio del logro académico, fue cuestionado ${ }^{68}$.

Los debates sobre la educación secundaria continuaron en los 1920, y tanto liberales como conservadores encontraron fallas en el sistema. Con el comienzo del movimiento de reforma de la universidad en este decenio, los estudiantes comenzaron a ser escuchados. Escribiendo en El Tiempo en 1921, Germán Arciniegas, líder estudiantil, manifestó que un gran número de graduados de bachillerato estaban perdiendo los exámenes de revisión, que se habían establecido en varias facultades de la universidad por iniciativa propia ${ }^{69}$. En su apoyo citó estadísticas de la Facultad de Medicina: 4 aprobados, 12 tolerados y 32 reprobados. Las presiones de ese año hicieron que la Facultad de Ingeniería de la Universidad estableciera un examen de revisión ${ }^{70}$. Con este crecimiento de popularidad de los exámenes de admisión, los Jesuitas renovaron sus argumentos de 1910; pero su posición no fue tan fuerte como antes. y los exámenes continuaron ${ }^{71}$.

Estos exámenes de admisión a comienzos de los 1920 habían sido un asunto no oficial que surgió por iniciativa de las facultades de la Universidad Nacional. En 1927, esta situación cambió con la Ley 56 , que estipulaba que todos los bachilleres tenían que aprobar un examen oficial de admisión si querían continuar sus estudios profesionales en

\footnotetext{
64 «Instrucción Pública: Causas de la decadencia». El Diario Nacional, año II, No. 292, 30 de agosto de 1916.p. 1.

65 Ibid.

66 Ibid.

${ }^{67}$ «A propósito de la instrucción pública». El Diario Nacional, año II, № 270, 16 de agosto de I9l6, p. 1.

${ }^{68}$ Ibid.

${ }^{69}$ Germán Arciniegas. «El bien que puede resultar de los Fracasos. El Tiempo. año XI. No. 3375.14 de febrero de 1921.

${ }_{71}^{70}$ «Se acepta el fracaso?» El Tiempo, año XI, No. 3382, 21 de febrero de 1921, p. 1.

${ }^{71}$ «la instrucción nacional y los pequeños intereses creados», El Tiempo, año XI. No. 3411. 22 de marzo de 1921. p. 5.
} 
la Universidad Nacional ${ }^{72}$. Para 1928 éste había sido aceptado. Aun los Jesuitas se vieron forzados a reconocer y a aceptar la existencia de estos exámenes. Un grupo de rectores, entre los que se contaba el de San Bartolomé, solicitó en 1928 algunas modificaciones del procedimiento de los exámenes en relación con el tiempo y el lugar. Sin embargo, no hicieron esfuerzos para buscar su abolición ${ }^{73}$.

La educación secundaria de ningún modo fue la única área crítica en la educación colombiana, ni tampoco fueron los liberales los únicos críticos de la calidad educativa. Más adelante, se examinarán tales confrontaciones y otros asuntos.

El Nuevo Tiempo, un periódico moderado influyente, pasó a ser altamente reservado con respecto a la educación colombiana. La escasez de cursos prácticos y el espíritu académico dominante se contaron entre sus blancos principales ${ }^{74}$. Una de sus críticas más drásticas a la educación colombiana se publicó el 23 de mayo de 1907, bajo el título «Reformas necesarias» ${ }^{75}$. Este artículo cuestionó el valor de la educación colombiana con su énfasis en las profesiones y los métodos tradicionales y su desatención a las áreas más técnicas, como minería, comercio, agricultura e ingeniería civil ${ }^{76}$. Se propuso como solución la substitución de las clases de gramática y de religión por las ciencias naturales en los colegios de primaria. Esta sugerencia pretendía iniciar a los niños tempranamente en el aprendizaje por medio de la observación y los sentidos ${ }^{77}$. La justificación de la propuesta se basaba en que el uso de los sentidos es más fácil para los niños menores que el uso de la razón, la cual era necesaria para asignaturas como la gramática y la religión.

No sobra decir que la reacción de la Iglesia fue rápida y definitiva. Esta elevación de la ciencia y del aprendizaje basado en los sentidos chocaba de frente con los conceptos tradicionales de la Iglesia y la idea de eliminar el catecismo de los primeros años de la primaria fue inaceptable, puesto que la gran mayoría de los estudiantes colombianos abandonaban el colegio después de sólo dos años de estudio. En una nota oficial del Arzobispo de Bogotá, publicada el 27 de mayo, la Iglesia aclaró su posición. El Arzobispo Bernardo Herrera fue especialmente crítico de la substitución del catecismo por la física y la historia natural en los primeros años de colegio. Tal substitución chocaba directamente con la idea de la Iglesia de que la religión era el ingrediente mas esencial en la formación temprana de los niños ${ }^{78}$. El Arzobispo aclaró que la tradición, la Constitución y el Concordato estaban del lado de la Iglesia, y que quienquiera que cuestionara su posición podía esperar consecuencias severas. Esta amenaza no podía tomarse a la ligera y El Nuevo Tiempo pareció no tener sino elogios moderados para la educación colombiana al finalizar el año académico. ${ }^{79}$

Los dardos contra la educación colombiana por parte de los moderados y los radicales continuaron durante los años restantes de la Regeneración. Las mismas quejas aparecían una y otra vez: los prejuicios imprácticos y no técnicos de la educación colombiana, los

\footnotetext{
${ }_{72}^{72}$ Ministerio de Educación Nacional, Educación Colombiana tiomo 1. op. cit., p. 68.

${ }^{73}$ «Los rectores de los colegios de segunda enseñanza...». El Debate año II. No. 394. 27 de junio de 1928.p. 1.

${ }_{75}^{74}$ «Instrucción Publica», Nuevo Tiempo. año V. No. 1335, 27 de junio de 1906. p. 2.

75 «Reformas necesarias». Nuevo Tiempo. año VI. No. 1644, 23 de mayo de 1907. p.2.

${ }^{76}$ Ibid.

77 Ibid.

78 " Nota oficial Arquidiócesis de Bogotá. Gobierno eclesiástico. No. 13, Bogotá 27 de mayo de 1907. en Bernardo Herrera Restrepo. Pastorales, tomo II. p. 347.

${ }^{79}$ «Progresos de la instrucción publica». Nuevo Tiempo. No. 1828, 27 de noviembre de 1907. p 2.

Digitalizado por RED ACADEMICA
} 
métodos dogmáticos de enseñanza y la influencia agobiante de la Iglesia católica ${ }^{80}$. Por supuesto, ésta defendió el status quo educativo y previno en contra del liberalismo creciente $^{81}$. Los educadores católicos como Rafael María Carrasquilla, que consideraban el currículo clásico corno una clave para el desarrollo de la mente, adelantaron una estrategia para combinar lo mejor del sistema antiguo con lo mejor del nuevo ${ }^{82}$. Dc acuerdo con tales educadores, la pedagogía católica no era antimoderna. La Iglesia estaba únicamente en contra de aquellos aspectos de la educación moderna que desafiaban el dogma y las creencias. Sin embargo, el fundamento mismo de la pedagogía moderna, con su énfasis en la importancia de los sentidos en el desarrollo inicial del niño, originó la reacción católica en su contra. Estas reacciones retardaron las técnicas y los métodos educativos modernos e impulsaron lo clásico y lo tradicional durante la Regeneración.

\section{Cuantificación de la educación}

El último tema de discusión tiene que ver con el número de colegios establecidos durante la Regeneración. Este asunto está íntimamente ligado a su vez con las ideas sobre la educación popular y obligatoria, a la cual se oponía la Iglesia. Más adelante examinaremos en forma concisa la disputa que se desarrolló sobre estos temas.

Se ha visto que el tipo de educación ofrecida por la política de la Regeneración estuvo sujeto casi de inmediato a fuertes críticas, entre las que se incluían afirmaciones en el sentido de que el crecimiento de la cantidad de la educación se «había reducido con el regreso de los conservadores» y con la abolición de la ley liberal sobre la obligatoriedad de la educación. En su artículo de 1896, Estado actual, Martínez Silva señaló el hecho de que los colegios colombianos estaban, de lejos, educando menos niños de lo que debían. Solamente el Departamento de Antioquia parecía estar haciendo un trabajo notable, con una población de 550.000 y unos 20.000 estudiantes. Cundinamarca. con una población de 600.000 , tenía 11.260 estudiantes en sus colegios ${ }^{83}$.

Más tarde, durante el mismo decenio, lo que parecía una desastrosa verdad estadística fue expuesta por funcionarios del gobierno. Su apoyo a la Regeneración hace más confiables sus afirmaciones. En una carta al Correo Nacional, fechada en enero de 1899. el secretario de Educación de Cundinamarca comparó las estadísticas educativas de 1875 con las de 1898. La comparación es desfavorable para el gobierno conservador. Aunque resaltaba que su fe católica le imposibilitaba defender una ley de educación obligatoria, no había por qué rechazar el progreso y el crecimiento de los $1870^{84}$, cuando existía tal ley. Calculó que en 1875 una tercera parte de los niños en edad escolar asistía a los colegios, mientras que en 1895 se acercaba a apenas tina sexta parte. Este funcionario también observó que la ayuda y el apoyo educativos del gobierno fueron mucho más amplios también en los 1870 que en los $1890^{85}$.

A finales de la Regeneración se dio periódicamente en la prensa la batalla de las estadísticas: ellas se utilizaron para criticar el estado de la educación y las

\footnotetext{
${ }^{80}$ Véanse por ejemplo: «La instrucción pública en Bogotá». Nuevo Tiempo, año XI. No. 3419.22 de enero de 1912, p. 2: «Acción educativa». Nuevo Tiempo, año XV. No. 5119, 3 de abril de 1917. p. 1: «Reforma de la instrucción», Nuevo Tiempo, año XVII. No. 6089. 16 de Diciembre de 1919, p. 1: «Nuestros sistemas de enseñanza». El Diario Nacional. año I. No. 83, 22 de diciembre de 1915, p. 1

81 "Véase: instrucción pública». La .Sociedad, año IV. ser. 26. No. 1003, 1 de abril de 1914. p. 1

${ }^{82}$ Raúl María Carrasquilla. Sobre educación Moderna (Medellín: Tip. Betancourt). 16 pp.

${ }^{83}$ Carlos Martínez Silva. op. cit.. p. 303.

${ }^{84}$ "Amarga verdad», El Correo Nacional, año IX. No. 2381.26 de enero de 1899, p. 2.

85 Ibid. 
comparaciones se hicieron siempre con la «edad de oro». Se hicieron, no obstante, algunas comparaciones favorables; por ejemplo, las cartas al editor citaban con frecuencia el hecho de que la educación colombiana estaba creciendo a pesar de la falta de una ley sobre la obligatoriedad. El Departamento de Antioquia dio un salto de 232 colegios con 16.511 estudiantes en 1883 a 695 colegios con 72.799 estudiantes en $1909^{86}$. En debates frecuentes en el Congreso en pleno los moderados y los católicos ortodoxos mostraron con entusiasmo este hecho de crecimiento educativo sin una ley que la hiciera obligatoria ${ }^{87}$. Al menos un congresista conservador afirmó que el número de estudiantes de los colegios de primaria oficiales en 1907 (240.296) estaba por encima del triple del número de estudiantes de los colegios oficiales y privados en 1876. Señaló que con una población de 2.951.323. el Partido Liberal había ayudado a $0.65 \%$ de los colegios, mientras que el Partido Conservador educaba en 1907 el $6.8 \%$ de una población de 4 millones en los colegios de primaria, diurnos y nocturnos ${ }^{88}$.

Sin embargo, las quejas, no la defensa, dominaron y aun los moderados consideraron el asunto de la educación popular como uno de los mayores problemas que afrontaba la educación co1ombiana ${ }^{89}$. Las estadísticas se utilizaron para mostrar las deficiencias y las agudas desigualdades entre los departamentos. Se observó que en al área de Bogotá, con unos de 127.000 habitantes, solamente $2,6 \%$ de la población, asistía a los colegios, mientras que en Antioquia la cifra se acercaba a $10 \%$ en 1912. Cauca y Antioquia, con sistemas educativos altamente desarrollados, por lo general ocupaban los primeros lugares en las listas más importantes que describen el progreso educativo en el país. Con una población de 5 millones en 1911, Colombia debería haber tenido una población estudiantil de un millón aproximadamente. En realidad ésta estaba por debajo de los 300 mil (272.873 para ser exactos) ${ }^{90}$.

\section{Expansión del momento de reforma y reacción. 1915-1930}

Como se ha visto, durante la Regeneración la educación pública colombiana fue fuente de conflicto entre tres grupos claramente diferenciados. Los liberales presionaron en favor de un cambio radical, un regreso a los días de una educación libre, laica y obligatoria y la influencia educativa de la Iglesia estuvo en su mira. De otra parte, los conservadores católicos vieron muy bien la situación del momento y lucharon por conservar este statu quo. Los moderados buscaron la reforma, pero dentro del establecimiento; este grupo sentía que la época moderna requería un cambio y apoyaban las reformas moderadas como la del proyecto de Ley de $1912^{91}$. En los años finales de Regeneración todos los tres grupos participaron en un vigoroso y tormentoso período de reforma y reacción.

El año de 1915 fue testigo de un empuje en favor de la reforma educativa en Colombia. Muchos colombianos estuvieron a favor de ésta, pero en particular podrían señalarse dos connotadas personalidades. El primero fue Agustín Nieto Caballero, el fundador y más conocido rector del Gimnasio Moderno de Bogotá. Durante los últimos años de la Regeneración se convirtió en el crítico más ardiente y diplomático del sistema y un denodado defensor de John Dewey y de la escuela activa. A mediados de 1915, escribió un artículo en El Tiempo, que causó amplio revuelo e interés por el llamado a una

\footnotetext{
${ }^{86}$ «Educación en Antioquia», Nuevo Tiempo. año IX. No. 2675. 7 de mayo de 1910, 2.

87 «De instrucción pública». La Sociedad, año II, ser. 8. No. 310, 21 de diciembre de 1911. p. 2.

88 Ibid.

${ }^{89}$ Por ejemplo, véanse: «El problema de la educación». Nuevo Tiempo, 10 de septiembre de 1913. p. 2: «Por la educación popular». Nuevo Tiempo, 5 de febrero dc 1918. p. 1.

${ }_{90}$ «El estado de la instrucción pública en Colombia». Nuevo Tiempo. 2 de septiembre de 1912, p. 2.

91 "Proyecto de Ley sobre instrucción pública». en Archivo del Congreso Camara. 1912. tomo II. pp. 541f$543 f$.
} 
completa reforma de la educación normalista en Colombia ${ }^{92}$. Como la Escuela Normal Central de Bogotá estaba bajo la dirección francesa de los Hermanos Cristianos, el llamado de Nieto en favor de una escuela normal científica de un verdadero carácter nacionalista fue asumido como un ataque a la Iglesia.

Más tarde, ese mismo año, una vez más Nieto Caballero contribuyó al mornentum de la reforma con una síntesis educativa presentada a la Convención Política Nacional Republicana ${ }^{93}$. Este documento fue muy crítico de los métodos arcaicos y de la educación normalista. Maestros, edificaciones y materiales, todo necesitaba drásticas mejorías. Pero sobre todo, los métodos educativos tradicionales tenían que ser reemplazados por unos más modernos y participativos y de orientación profesional ${ }^{94}$.

Agustín Nieto Caballero había despertado el interés por la reforma; pero el impulso que se necesitaba para estimular un debate educativo permanente durante 1916 provino de Enrique Olaya Herrera y su periódico El Diario Nacional. Olaya Herrera habría de ser el primer presidente liberal moderado elegido en Colombia después de cincuenta años de gobierno conservador (1930). En esa temprana fecha, empero, estaba primordialmente dedicado al periodismo político, y en diciembre de 1915 su periódico inició un examen de la educación que estimuló un gran debate nacional. La iniciativa estaba basada en la pregunta: ¿Qué cambios esenciales piensa que necesitan los actuales programas de secundaria y qué cambios básicos requiere nuestro sistema educativo ${ }^{95}$. Las respuestas de los educadores colombianos se publicaron en el periódico a partir del 15 de diciembre y continuaron hasta bien entrado 1916.

Las respuestas provinieron de variados sectores de educadores colombianos, clérigos y laicos, liberales y conservadores. Los liberales estaban representados por hombres como el Dr. Eugenio J. Gómez, rector de la Universidad Republicana, y de Deudoro Aponte, quienes consideraron el sistema como «arcaico» y "clásico» ${ }^{96}$. Se necesitaban más ciencia y matemáticas, más educación práctica para la vida, más observación y experimentos en los colegios, que ayudaran a formar mentes que pensaran con independencia $^{97}$. Los métodos dogmáticos de enseñanza y la excesiva influencia de la Iglesia fueron los objetivos preferidos de estos educadores liberales. ${ }^{98}$.

Por otra parte, los educadores católicos como Martín Restrepo Mejía contestaron a la encuesta de una manera menos radical. Lo importante, sin embargo, es que aun estos educadores vieron la necesidad de alguna clase de reforma. La petición más usual fue más dinero, menos política y burocracia. junto con estándares más rígidos y mejor organización ${ }^{99}$. La literatura y la filosofía conservaron su posición de asignaturas favoritas de estos educadores y sus actitudes tradicionales en lo referente a la educación femenina fueron evidentes ${ }^{100}$.

\footnotetext{
${ }_{93}^{92}$ Agustín Nieto Caballero. «La reforma educacionista». El Tiempo 6 de junio de 1912.

${ }_{93}$ «la reforma escolar». El Tiempo. 18 d julio de 1915. p. 2.

${ }^{94}$ Ibid.

95 «Encuesta de El Diario», El Diario Nacional, año I. No. 82, 21 de diciembre de 1915. p. 1.

96 ibid.

${ }^{97}$ Deudoro Aponte. «Fracaso de la instrucción pública», El Diario Nacional. año II. No. 100, 13 de enero de 1916. p. 2.

98 ibid.

${ }^{99}$ Martín Restrepo Mejía. «Nuestros sistemas de enseñanza». El Diario Nacional, 22 de diciembre de 1915. p. 2.

${ }_{100}$ ibid. 
Desde los comienzos, la reacción frente a la reforma fue fuerte. La prensa liberal la abrazó de todo corazón. Ya desde el 30 de diciembre de 1915 en su editorial, El Espectador calificaba a la Iglesia como el principal impedimento para la reforma, puesto que cualquier esfuerzo en su favor era rotulado como de anticlerical ${ }^{101}$. Este problema, que se debía a la avasalladora influencia de la Iglesia en la educación pública, continuó acosando a los reformistas durante la Regeneración. Se consideró la palabra «reforma» corno una amenaza contra el poder de la Iglesia ${ }^{102}$.

La prensa liberal reaccionó ante la encuesta y a la cuestión de la reforma durante todo el año de 1916. Todos los aspectos de la educación colombiana fueron tratados en los informes de El Tiempo y de El Espectador ${ }^{103}$. Algunos periódicos conservadores, como La Unidad dirigido por Laureano Gómez. también apoyaron reformas fundamentales, en especial en la secundaria y en la formación de normalistas ${ }^{104}$. Los aspectos de calidad y cantidad aparecieron en el debate educativo y los liberales hicieron gala de las estadísticas anteriores a 1885 y reeditaron sus condenas al sistema ${ }^{105}$. La prensa conservadora se apresuró a contar con sus propias estadísticas y presentaciones en defensa de la libertad de enseñanza y a criticar la penetración del materialismo en el sistema educativo ${ }^{106}$.

Los retos seculares al statu quo de la educación estimularon respuestas rápidas de la Iglesia, que defendió la tradición clásica, al igual que los métodos de enseñanza de comunidades como las de los Jesuitas y los Hermanos Cristianos ${ }^{107}$. En el Congreso se bloqueó una propuesta para secularizar la educación colombiana ${ }^{108}$, y la Iglesia resueltamente se defendió de quienes decían que tenía interés creado en el analfabetismo $^{109}$. Los educadores católicos como Rafael María Carrasquilla y Félix Restrepo S.J. defendieron obstinadamente el currículo clásico. Creían que la literatura y las lenguas clásicas eran los mejores caminos para el desarrollo intelectual ${ }^{110}$.

El debate educativo continuó durante los 1920. Los temas fueron los mismos, y las cuestiones de calidad y cantidad y la influencia educativa de ciertas comunidades religiosas encabezaron la lista. Sin embargo, durante estos años nuevas fuerzas también comenzaron a unirse a los críticos tradicionales. Una de ellas fue el movimiento estudiantil universitario de reforma. Las exigencias presentadas al Congreso en 1923 por los estudiantes fueron un llamado a la educación primaria libre, universal, gratuita y obligatoria, con énfasis en los métodos de observación y experimentación y más educación tecnológica ${ }^{111}$. Un sumario del estado deseado de la educación emitido en

\footnotetext{
101 «la reforma escolar». El Espectador. 30 de diciembre de 1915. p. 1.

102 ibid..

103 Por ejemplo, véase: «El pleno debate». El Espectador. 31 de marzo de 1916. p. 1.

104 «Sobre la reforma escolar». El Tiempo. año VI. No. 1623, 31 de marzo de 1916. p. 2.

105 «A propósito de la instrucción publica». El Diario Nacional, año II. No. 270, 2 de agosto de 1916. p.2:
} «Deficiencias de la enseñanza primaria, Estadísticas engañosas». El Diario Nacional. año II. No. 288.25 de agosto de 1916,p. 1.

${ }^{106}$ Véase: «Los colegios liberales, la ciencia y la tranquilidad pública». La Sociedad, año VII. ser. 47.No. 1878, 17de abril de 1917

107 .J.M. Restrepo Millán, «La enseñanza de los clásicos y la filosofía en Colombia», El Nuevo Tiempo, año XIV. No. 4671, 3 de enero de 1916. p. 3.

108 «Instrucción publica». El Diario Nacional, año II. No. 244. 1 de julio de 1916. p. 1.

109 «El republicanismo anticlerical y la historia patria». La .Sociedad. año VI. ser. 41. No. 1602, p. 2.

110 Véanse: «Rafael María Carrasquilla». «Sobre educación moderna. op. cit.: y Félix Restrepo. S. J.. «EI bachillerato en Colombia». Revista de instrucción Publica. tomo XXVIII. No. 9 y 10, sept. octubre de 1916, pp. 595-625.

«Manifestación de los estudiantes al Congreso». Nuevo Tiempo. año XXII. No. 7445.23 (le septiembre de 1923. p. 1. 
1930 por la Federación de Estudiantes chocó directamente con la Iglesia puesto que defendía la coeducación, la igualdad educativa para hombres y mujeres y una enseñanza objetiva, no subjetiva, de la religión y de la filosofía ${ }^{112}$. Esta declaración fue sonoramente condenada por la Iglesia por estar en directo conflicto con la ortodoxia católica y con varias encíclicas $^{113}$.

En la medida en que las nuevas fuerzas reaccionaban al momentum de la reforma educativa de los 1920, las viejas fuerzas continuaban su lucha. Agustín Nieto Caballero estimuló otro debate nacional en 1923 cuando envió una carta pública al Presidente Pedro Nel Ospina en la cual destacaba «una total carencia de educadores» en Colombia ${ }^{114}$. Escribió:

Con certeza podemos decir que hemos llegado a un periodo de mediocridad en la educación que podrá continuar si los métodos dogmáticos continúan predominando sobre lo intuitivo y lo experimental ${ }^{115}$.

El debate que siguió a la publicación de esta carta estuvo saturado de cargos de anticlericalismo. Se supuso que Nieto estaba dirigiendo su crítica directamente contra las comunidades religiosas docentes, las cuales ejercían una influencia exorbitante en la educación normalista de Colombia ${ }^{116}$. Sea como fuere. la esencia es que el argumento de Agustín Nieto Caballero tuvo audiencia y al año siguiente el gobierno invitó a una misión educativa alemana para que hiciera un amplio examen de la cuestión.

Entre tanto, la Iglesia continuó reaccionando frente a las presiones en favor de la reforma educativa y el cambio. Esta reacción puede clasificarse bajo tres encabezamientos: nacional, local e internacional. Los temas de esta reacción fueron básicamente los mismos: la preservación del poder de la Iglesia frente al interés creciente del Estado en la educación y la defensa de la tradición de la Iglesia en la educación pública. El apoyo a las ideas de libertad de la educación y la educación no obligatoria también figuran con gran peso en la reacción católica ${ }^{117}$. La diferencia radicó en el énfasis, pues a medida que el decenio de 1920 maduraba, la Iglesia daba señales crecientes de buena voluntad para la conciliación y la moderación a la luz de las crecientes demandas del Estado. Como siempre, la Iglesia tuvo la capacidad de modificar anteriores posturas inmodificables.

En el ámbito nacional, las conferencias episcopales desafiaron las tendencias a la reforma educativa. En estas conferencias la jerarquía católica exigió un cumplimiento estricto de la ortodoxia educativa del artículo 41 y del Concordato y en la Conferencia de 1918 se recomendaron tácticas muy evocadoras de las de los decenios de 1880 y 1890 , y se hizo énfasis en el papel de "perro guardián» de los sacerdotes ${ }^{118}$. En 1924 los obispos sintieron que se estaban haciendo incursiones anticatólicas en la educación, y

\footnotetext{
112 «La Federación y la reforma instruccionista». La Crónica Universitaria. publicación de la federación de Estudiantes de Colombia, No. 1, 26 de abril de 1930, pp. 19-28.

113 «Exposición». La Iglesia. 1 de noviembre de 1930, pp. 333-348.

114 Agustín Nieto Caballero, «Carta al Presidente de la República sobre el problema de la educación nacional». Santa Fe de Bogotá. 30 de junio de 1923, pp. 42-43. Del archivo personal de Agustín Nieto Caballero.

115 Ibid

${ }^{116}$ Véase: R. Escobar Roa, «El problema de la educación nacional», Nuevo Tiempo.17 de ,julio de 1923: y cartas de Escobar Roa a Nieto Caballero en Nuevo Tiempo, 20 de agosto de 1923.

117 «La Asamblea del Valle y los Hermanos Maristas». Nuevo Tiempo, año XXII, 3 de agosto de 1923. p. 1: «El bachillerato y la libertad de enseñanza». El Debate, año 1, No. 263. 14 de febrero de 1928. p. 4.

118 «Conferencia episcopal», Revista Diocesana, Socorro, año XVII, No. 8, 27 de febrero de 1918. pp. 57-59. 
advirtieron la cantidad de peligros específicamente censurados por Pío IX en su Syllabus errorum ${ }^{119}$.

En el nivel local, en forma individual los obispos dieron pasos para preservar la ortodoxia católica en el sistema de colegios públicos. En los primeros años de los 1920 el Arzobispo Bernardo Herrera fue menos enérgico, pero aun estaba más o menos activo. En la Costa el Arzobispo Brioschi mostró un extraordinario dinamismo en sus esfuerzos por preservar la ortodoxia católica. El arzobispo Manuel José Benítez de Medellín se ocupó también de ejercer presión para que los curas párrocos inspeccionaran y examinaran la moral y los aspectos religiosos de la educación pública. Emprendió una constante batalla para reforzar las clases de religión y catecismo a la luz de lo que él denominó modernismo avasallador, es decir. más matemáticas, ciencias naturales y lenguas extranjeras ${ }^{120}$. La vigilancia contra el modernismo pedagógico era la prioridad, lo que incluía la censura desde un profesor universitario hasta un miembro de una comunidad religiosa docente ${ }^{121}$.

Mientras la reacción católica nacional se esforzaba por retardar el momento de la reforma, algo también sucedía en el campo internacional. En enero de 1923, el Nuncio papal en Bogotá entró en la política educativa nacional con dos circulares secretas a los obispos de Colombia. La primera, fechada el 4 de enero de 1923, criticaba duramente el estado de la educación en Colombia y aconsejaba una estricta imposición del Concordato y más énfasis en la educación religiosa ${ }^{122}$. La segunda circular, con la misma fecha, sugería la suspensión de los días libres en los colegios católicos de bachillerato ${ }^{123}$. Ambas circulares fueron clasificadas como correspondencia privada porque si se hubiesen hecho públicas, el Obispo Vicentini hubiera quedado expuesto a la crítica como el representante de una organización internacional que se inmiscuía indebidamente en un asunto interno de Colombia ${ }^{124}$.

Una declaración pública de Vicentini en febrero del mismo año en efecto lo convirtió en objetivo de tales ataques. El 4 de febrero de 1923 se le cita como autor de una declaración en el sentido de que la reforma debería realizarse dentro de los limites del Concordato "... evitando de esta manera cualquier posibilidad de protesta oficial por el Nuncio apostólico en el ejercicio de sus derechos diplomáticos apoyados por el Derecho Internacional"125. La reacción a esta declaración varió según la afiliación política. Para el pensamiento conservador, era lógico que la Iglesia hiciera valer su autoridad en la reforma educativa colombiana ${ }^{126}$. Sin embargo, el Nuncio papal había tocado un área muy delicada de la soberanía nacional, lo que causó enorme revuelo. Los liberales defendieron

\footnotetext{
119 Pastoral colectiva de los prelados congregados en la Cuarta Conferencia Episcopal Colombiana (Bogotá: Impr. de San Bernardo. 1924), pp. 7-8.

${ }^{20}$ Archivo de la Arquidiócesis de Medellín, carta de Manuel José a Tomás David Restrepo. 14 de marzo de 1928; también carta de Manuel José Benítez a Raúl Vélez. Director de varones de la Normal, 15 de abril de 1928.

${ }^{121}$ Archivo de la Arquidiócesis de Medellín. carta de Manuel José Benítez a los delegados Apostólicos, 4 de febrero de 1923.

${ }^{122}$ Archivo de la Arquidiócesis de Medellín. carta de Roberto Vicentini. Nuncio Apostólico a los obispos colombianos. 4 de enero de 1923. (Copia No. 136.)

${ }^{123}$ Archivo de la Arquidiócesis de Medellín. carta de Roberto Vicentini a los obispos colombianos. 4 de enero de 1923. (Copia No. 137.)

${ }^{124}$ Archivo de la Arquidiócesis de Medellín, memorando que acompaña dos cartas del Nuncio apostólico, fechadas el 4 de enero de 1923. (Copia No. 138.)

${ }_{125}$ "Con Monseñor Vicentini», El Nuevo Tiempo, año XXII, No. 7483, 11 de noviembre de 1923. p. 1.

${ }^{126}$ Ibid. 
la soberanía del Estado para hacer la reforma sin la interferencia de la Iglesia. La reacción que condenaba la actitud de la Iglesia fue acalorada y feroz ${ }^{127}$.

La amenaza del clericalismo internacional no continuó y quedo pospuesta para los debates educativos del año siguiente ${ }^{128}$. Tal vez esta publicidad adversa hizo que la Iglesia mitigara su filosofía y en 1924 dio una aparente media vuelta, inclinándose ante la inevitabilidad de la llegada de la misión educativa extranjera. La Iglesia no abrigaba grandes esperanzas en la misión si ésta se apegaba a la reforma educativa ${ }^{129}$.

Si bien la reacción inicial de la Iglesia a la Misión Alemana fue favorable, su reacción posterior ante sus propuestas legislativas no lo fue. Los periódicos católicos y moderados dejaron en claro que la Iglesia favorecía los métodos de la educación moderna y el interés del Estado en la educación y, en un completo cambio de política, afirmaron que la Iglesia podría llegar a aceptar una ley de educación obligatoria siempre y cuando la educación no quedase limitada a los colegios oficiales ${ }^{130}$. Sin embargo, se opuso al monopolio de la educación por el Estado; la evidencia de esta oposición se encuentra en el proyecto de ley de reforma presentado por la Misión Alemana. La prensa católica, encabezada por La Iglesia, condenó la idea del control de los estándares educativos y de los currículos por el Estado como una amenaza directa en contra de la educación católica privada. Las partes del decreto que concedían ventajas a los colegios estatales y a sus graduados fueron severamente atacadas ${ }^{131}$. Se presentó oposición a que el Estado confiriera títulos oficiales a los profesores porque tal acción se consideraría como una amenaza para las comunidades religiosas docentes, al igual que los exámenes de admisión a la universidad, que se basaban exclusivamente en los programas oficiales ${ }^{132}$. El proyecto de ley representaba un reto para el poder de la educación católica, en especial en la secundaria. Las modificaciones sugeridas por La Iglesia incluían los derechos de las comunidades religiosas para enseñar en las escuelas públicas de primaria, para otorgar el título de bachiller y para conceder las credenciales de enseñanza a sus propios miembros. Los párrocos conservaban el derecho de inspeccionar las escuelas y se preservaba la ortodoxia católica en las aulas ${ }^{133}$.

El proyecto de ley de reforma de 1925 no se aprobó en el Congreso. Un decreto más conservador sufrió la misma suerte en 1926. Sin embargo, el año siguiente demostró ser un punto de retorno para el cambio educativo y la reforma, señal de que estaba culminando una época. En 1927 el gobierno se rehusó a renovar el contrato con los Jesuitas, que había estado en vigencia desde 1886. Esta decisión fue sancionada oficialmente por el Decreto \# 1951 de 1927, que abolió la educación secundaria oficial, la cual era primordialmente jesuita. También concedió al Estado más poder para el control, la organización y la inspección de los colegios privados de secundaria. Si los estudiantes de los colegios de secundaria pretendían ingresar a la Universidad Nacional, sus colegios tenían que seguir las normas y programas del Ministerio de Educación y permitir la

\footnotetext{
127 «La prensa de Bogotá-Cuestión de soberanía», La República, año III, No. 812, 13 de noviembre de 1923, p. 2.

${ }_{128}$ «La instrucción pública». El Catolicismo, año III, No. 171, 1 de octubre de 1924, p. 1: «Clericalismo internacional», El Catolicismo, año III. No. 183, 12 de noviembre de 1924. p. 1

${ }_{129}$ "La misión pedagógica», El Catolicismo, año III. 3 de diciembre de 1924, p. 1.

130 «Observaciones al proyecto de ley sobre instrucción (1925)». la iglesia, año XX. No. 8.30 de septiembre de 1925. p. 231.

${ }_{131}$ Ibid., pp. 238-239.

${ }^{132}$ Ibid., pp. 241-242.

133 Ibid., pp. 237. 
verificación de este hecho ${ }^{134}$. La Ley 56 del mismo año limitó el derecho de graduar bachilleres a aquellos colegios que habían recibido este privilegio del Ministerio. También hizo que el examen de admisión a la universidad fuese obligatorio y declaró que la educación era «gratuita» y «obligatoria» ${ }^{135}$.

La reacción liberal fue de entusiasmo ante los avances de 1927. El Tiempo calificó el decreto 1951 como «... un triunfo del sentido común y de la justicia después de 40 años de irritantes intereses creados» ${ }^{136}$. Se abrigaban altas esperanzas para la educación secundaria ahora que el estado abandonaba su actitud de laissez faire. En la polémica que siguió, el Ministro de Educación siguió defendiendo su decisión afirmando que el gobierno no estaba obligado a mantener los colegios oficiales ${ }^{137}$. También mitigó su posición asegurando a los Jesuitas que el San Bartolomé y otros colegios jesuitas continuarían recibiendo ayuda del Estado ${ }^{138}$. En efecto, la ley 44 de 1928 concedió al San Bartolomé la «autonomía» bajo la administración de los Jesuitas y les otorgó 65 becas ${ }^{139}$.

La reacción contra los hechos de 1927 fue dirigida por los Jesuitas y sus simpatizantes en la prensa católica. Se emplearon los argumentos tradicionales: los temores por el monopolio del Estado y las amenazas a la libertad de educación y a la educación privada $^{140}$. Una petición de los exalumnos del San Bartolomé publicada en El Debate el 2 de febrero de 1928 pedía la abolición inmediata del decreto alegando que violaba el artículo 4 de la Ley 39 de 1903 al eliminar la educación oficial ${ }^{141}$. También se emplearon argumentos económicos $^{142}$. Por último, un panfleto titulado Estudio sobre el decreto 1951 de 1927, escrito por Jesús M. Fernández, S.J. en 1928, resumió la posición jesuita. Fernández enfatizaba que la igualdad de la educación secundaria podría ayudar a la alternativa de las escuelas protestantes, y que la creciente influencia del gobierno tenía tufillo de Estado docente ${ }^{143}$. A pesar de la reacción católica. el Consejo de Estado aprobó este decreto, entre horrendas predicciones de un renacimiento de una educación protestante en Colombia y de la inanición económica para los colegios católicos ${ }^{144}$.

Después de los sucesos de 1927 y 1928. la Iglesia más que nunca se empeñó en defender su posición a la luz del crecimiento de la presencia del Estado en la educación colombiana. Las pastorales del Arzobispo Ismael Perdomo revisaron las relaciones en el campo de la educación entre la Iglesia y el Estado. La primera era educadora por derecho de la ley, mientras que éste tenía fundamentalmente una función de apoyo en la educación. También se acentuó el aspecto del derecho moral y legal de la Iglesia a la inspección y a la censura. La Conferencia Episcopal de 1928 hizo hincapié en que la ortodoxia y el control ocupaban una posición alta en la lista de la Iglesia en su lucha por conservar su posición en la educación colombiana; y las recomendaciones sobre el catecismo, la inspección local, las clases y las prácticas de la religión y la censura se reimprimieron en todo el país. Por último, dos cartas pastorales de 1930 emanadas del

\footnotetext{
134 Jesús M. Fernández, S. J., Estudio sobre el decreto /95/ de 1927 (Bogotá: Sociedad Editorial. 1928), p. 28.

${ }^{135}$ Disposiciones vigentes sobre instrucción pública de $192 T$ a 1933 (Bogotá: Imprenta Nacional. 1933). pp. 18-21.

136 «La libertad de la segunda enseñanza». El Tiempo. año XVII. No. 5818. 5 de diciembre de 1927. p. 3.

137 «habla el Ministro de Educación sobre el decreto». El Debate, año I. No. 250. 3 de febrero de 1928. p. 1.

138 Ibid.

139 Disposiciones vigentes ..., op. cit., p. 49.

140 El reportaje del Ministro de Educación». El Debate, año I. No. 251, 4 de febrero de 1928. p. 4.

141 «El decreto sobre instrucción pública». El Debate, año I. No. 249, 2 de febrero de 1928, p. 1.

142 Ibid.

143 Jesús M. Fernández. S. J., Estudio... op. cit., pp. 13-18.

144 «El Consejo de Estado ...» El Debate. año I. No. 273, 26 de febrero de 1928. p. 1. 
Palacio Arzobispal de Bogotá repasaron ampliamente la posición moral y legal de la Iglesia en la educación colombiana y recalcaron que la aprobación eclesiástica de los colegios requería de la ortodoxia tanto en los programas como en relación a los docentes $^{145}$.

La Iglesia católica resistió vigorosamente el cambio; pero con el decreto de 1927 había llegado el fin de una era. Con toda seguridad, la Iglesia continuó ejerciendo su influencia en los círculos educativos después de 1930, aunque jamás sería otra vez la influencia dominante en la educación colombiana.

\section{Conclusión}

La Regeneración (1886-1930) es uno de los períodos mas fascinantes de la historia reciente de Colombia. Es un período en el cual resurgieron muchas de las características y tradiciones del pasado colonial, en agudo contraste con los periodos de reforma y de reacción liberal que le antecedieron y le siguieron. Este giro de los acontecimientos se dio en el decenio de 1880, uno de los más importantes en la historia colombiana del siglo XIX. Durante esos años culminó un giro de la filosofía y el poder políticos. Bajo la dirección de Rafael Núñez y de Miguel Antonio Caro, el Partido Conservador colombiano fue capaz de reconquistar su perdido poder político y de retenerlo por 40 años. Este desarrollo de los acontecimientos favoreció grandemente a la Iglesia católica, y la Constitución de 1886 devolvió a la Iglesia los derechos y los privilegios que había perdido en la educación pública y privada.

La Constitución de 1886 legitimó el poder educativo de la Iglesia. La educación pública debió conformarse dentro del dogma y la moral católicos. El Concordato firmado en 1887 entre el Vaticano y Colombia hizo eco de este sentimiento, a la vez que dio un paso más al garantizar a la Iglesia el derecho de inspección en los colegios públicos sobre todos los aspectos relacionados con la moral y la religión. El Concordato también consagró el derecho del Catolicismo a revisar los textos y supervisar a los profesores. Por último, durante los últimos años de ese decenio se aprobaron leyes y decretos que ayudaron a la consolidación de la orientación católica de la educación. Qué resultó de esta legitimación de la influencia católica en la educación, el impacto en los plazos corto y largo de la Iglesia sobre la educación durante la Regeneración, ha sido el tema del presente trabajo.

Uno de los resultados inmediatos de los cambios político-religiosos de los 1880 fue el retorno de las comunidades católicas docentes a una posición dominante en la educación colombiana. Tales comunidades desempeñaron un papel integral en el crecimiento y la expansión de la presencia católica en la educación colombiana durante la Regeneración. Fueron esencialmente las fuerzas de choque de la educación católica y tanto ellas como el Estado se beneficiaron de sus iniciativas. La Iglesia aprovechó estas comunidades para cimentar su influencia sobre el país y sus ciudadanos. Para el Estado, las comunidades docentes contratadas por los gobiernos nacional, departamental y local significaron, entre otras cosas, una educación a un costo más bajo. Finalmente, las comunidades religiosas docentes contribuyeron con mucho más que el fervor religioso a la educación colombiana. Comunidades como la de los Jesuitas, los Hermanos Cristianos y las Hermanas de la Presentación fueron en extremo influyentes en la formación de la élite, en el mejoramiento de los programas de estudio y en la educación femenina. El cambio radical de los acontecimientos en el decenio de 1880 llevó a otros resultados educativos: a que la

\footnotetext{
${ }^{145}$ Véase: «Exposición». La Iglesia, año XXIV, vol. XXIV, 1 de noviembre de 1930. pp. 333-348: «Circular del llustrísimo y Reverendísimo Sr. Arzobispo acerca de la educación cristiana de la juventud». La iglesia. año XXIV. Vol XXIV. sept./octubre de 1930 pp 292 - 362.
} 
Iglesia emprendiera una campaña para garantizar que las ideas «ortodoxas» prevalecieran en las aulas colombianas, a la cooperación económica del Estado en apoyo del desarrollo y el crecimiento educativo católico y a un gradual surgimiento de la Iglesia como una influencia cuantitativa preponderante en la educación colombiana. La campaña católica contra las ideas heterodoxas contempló la censura de las escuelas y los individuos que tuvieron la osadía de desafiar la autoridad de la Iglesia y el dogma católico. La Iglesia utilizó todas las armas que tuvo a su disposición, desde la censura pública hasta la excomunión. La cooperación del Estado con la Iglesia durante la Regeneración favoreció la rápida expansión y el desarrollo de la educación católica con su contribución en forma de becas y regalos, así como en donaciones consistentes en materiales y edificaciones, y por su apoyo moral básico. Por último, el impacto educativo de la Iglesia fue subrayado por su dominación en la secundaria, el bachillerato comercial y la educación técnica en Colombia y por su influencia avasalladora en el número anual de diplomas otorgados en el país a bachilleres clásicos, bachilleres comerciales y normalistas.

Tal vez el resultado más significativo de los cambios educativos durante la Regeneración fue el impacto de la Iglesia en la orientación total de la educación colombiana. Durante la Regeneración, la Iglesia y el Catolicismo permearon los programas escolares oficiales de todos los colegios públicos y de la mayor parte de los privados. Todos los colombianos que recibían educación pública necesitaban tomar clases de religión católica y participar en las prácticas de religión católica como parte del programa escolar. Con el retorno de la Iglesia se impulsó un enfoque más tradicional de la educación en Colombia. Los currículos clásicos y el elitismo educativo se convirtieron en los patrones rectores de la educación. La pedagogía católica. con su énfasis en la religión y en las actividades académicas, las rutinas estrictas, la competencia y la disciplina fueron otra vez el modelo educativo en Colombia.

Durante la Regeneración, muchos críticos encontraron fallas en esta clase de educación que, según decían, parecía ir más en reversa hacia lo tradicional, que avanzar hacia un tipo de educación más moderna. No obstante, estos críticos fueron equilibrados por un número aproximadamente igual de defensores, algo que le permitió a la Iglesia continuar ejerciendo su influencia desmedida en la dirección de la educación y de la sociedad colombianas de la época.

Subsiste el interrogante de qué ha significado esta influencia desmedida de la Iglesia durante la Regeneración para la historia posterior colombiana. Es difícil responder. Sin embargo, es cierto que las actitudes católicas tradicionales hacia la educación obligatoria, la educación de la mujer y los currículos clásicos retardaron el desarrollo de un sistema educativo más moderno, uno que hiciera énfasis en la educación de las masas y de un currículo de orientación secular. Además, por todas las apariencias, Colombia ha seguido siendo el país más católico de América Latina, si no del mundo. Sin duda, la influencia educativa formal y no formal de la Iglesia sobre la sociedad colombiana ha tenido mucho que ver con todo esto. Con certeza, el momentum alcanzado por la educación católica durante la Regeneración ha continuado. Las estadísticas del Análisis de la educación colombiana (1969) revelan que de cerca de 350.000 estudiantes colombianos de colegios de secundaria a mediados del decenio de 1960 , más de $40 \%$ estaban matriculados en colegios bajo el control directo de la Iglesia y sus comunidades religiosas docentes ${ }^{146}$. El ${ }^{146}$ Alberto Alvarado y Eduardo Carrasquilla, Análisis de la educación en Colombia (Bogotá: Centro de
Investigaciones y Acción Social, 1969). P.88. 
catolicismo aún continua ejerciendo una influencia visible en la formación de las élites colombianas 